\title{
Capture of Sprinkler Irrigation Water by Container-grown Ornamental Plants
}

\author{
Jeff B. Million' ${ }^{1}$ and Thomas H. Yeager \\ Department of Environmental Horticulture, University of Florida, IFAS, \\ 1545 Fifield Hall, Gainesville, FL 32611-0670
}

Additional index words. canopy, interception, nursery, overhead, spacing, species, wobbler

\begin{abstract}
The capacity for container-grown plants to capture sprinkler irrigation water plays a critical role in adjusting irrigation rates to deliver required amounts of water to the container substrate. The capture factor (CF) used to describe this capacity was defined as the amount of water captured with a plant relative to the amount captured without a plant. A wind-sheltered, irrigation test area was established to measure $\mathrm{CF}$ as affected by plant species, plant size, container size, container spacing, and sprinkler type. CF values for 11 marketable-sized, commonly grown plant species ranged from 1 to 4 with highest values exhibited by plant species with an upright, spreading growth habit. CF values increased as plant size increased. Close container spacings (less than one container diameter between adjacent containers) reduced $C F$ when the allotted area outside the container limited the potential amount of water that could be captured. Compared with impact sprinklers, wobbler sprinklers increased irrigation capture 7\% for Ligustrum japonicum grown in $27-\mathrm{cm}$-diameter containers but not in 16-cm-diameter containers. Results showed that $\mathrm{CF}$ is a dynamic parameter that depends on canopy size, container size, container spacing, and sprinkler type. A working knowledge of $\mathrm{CF}$ is crucial for determining irrigation requirements to maximize sprinkler irrigation efficiency in container nurseries.
\end{abstract}

The container nursery industry is facing severe restrictions on water use (Beeson et al., 2004). Container substrate water deficits can be measured directly by weighing (Beeson, 2011; Million et al., 2010; Owen et al., 2007), indirectly with sensors (Bergeron et al., 2004; Murray et al., 2004), or simulated with models and local weather data (Beeson, 2010; Million et al., 2011). Evapotranspiration (ET)-based irrigation scheduling, designed to apply water in proportion to plant demand, is being recommended as a best management practice for conserving water [Florida Department of Agriculture and Consumer Services (FDACS), 2014]. Although research has investigated ET from containers during production (Beeson, 2010; Schuch and Burger, 1997), comparatively little research has evaluated the ability of containerized plants to capture sprinkler irrigation water. Irrigation capture is important because containers occupy only a fraction of the production area even when closely spaced and there is potential for plant canopies to influence the proportion of sprinkler irrigation water that is captured relative to that which falls unintercepted between containers.

\footnotetext{
Received for publication 19 Nov. 2014. Accepted for publication 24 Dec. 2014.

This research was supported by the Southwest Florida Water Management District and Alafia River, Hillsborough River, Peace River, and Withlacoochee River Basin Boards. Mention of trade names does not constitute an endorsement.

${ }^{1}$ To whom reprint requests should be addressed; e-mailjmillion@ufl.edu.
}

We use the term CF to describe sprinkler irrigation capture:

$$
C F=\frac{V p}{V o},
$$

where $V_{p}=$ volume of sprinkler irrigation water captured by the container with a plan$\mathrm{t}$, and $V_{o}=$ volume of sprinkler irrigation water that would be captured by the same container without a plant. CF greater than 1 indicates the plant canopy is capturing water that would otherwise fall between containers. CF less than 1 indicates the plant canopy is directing water outside the container that would otherwise fall into the container. Finally, $\mathrm{CF}=1$ indicates the plant canopy has no measurable effect on irrigation capture. Although the volume of water is measured during $\mathrm{CF}$ testing, equivalent depth of water $(\mathrm{cm})$ can be calculated by dividing the volume of water $\left(\mathrm{cm}^{3}\right)$ by the top area of the container $\left(\mathrm{cm}^{2}\right)$.

Few studies were found that investigated the capture of sprinkler irrigation by container-grown plants. Beeson and Knox (1991) reported CF less than 1 for two Rhododendron species and Pittosporum tobira indicating that these three species directed water away from the container. CF was inversely proportional to plant leaf area and decreased at close container spacings. Beeson and Yeager (2003) measured irrigation capture by marketable-sized Viburnum odoratissimum, Ligustrum japonicum, and Rhododendron spp. in 23-cm-diameter containers spaced from 0 to $51 \mathrm{~cm}$ between containers in a square pattern. For plants spaced in this range, $\mathrm{CF}$ increased linearly from 0.5 to 1.2 for
Viburnum odoratissimum and from 0.6 to 1.0 for Ligustrum japonicum. At the widest space, CF measurements for Viburnum odoratissimum ranged from 0.5 to 1.8 indicating considerable variation between plants. The CF for Rhododendron spp. was not greatly affected by container spacing with values ranging from 0.6 to 0.7 . Although a wide range of plant sizes was not evaluated, $\mathrm{CF}$ was positively correlated with total plant leaf area and plant size.

Plant characteristics may affect irrigation capture. Bilderback et al. (2011) observed that plant architecture influences irrigation capture. Cotoneaster dammeri with an umbrella-shaped canopy exhibited $\mathrm{CF}=1$, whereas Gardenia jasminoides and Vitex trifolia, both with upright spreading architecture, exhibited $\mathrm{CF}=2.5$. Viburnum odoratissimum, a woody ornamental with an upright spreading habit, grown in 16-cm-diameter containers had CF measured every 3 weeks during production (Million et al., 2010). CF was equal to 1 until plant size index (average of plant height and plant width) exceeded container diameter at which time $\mathrm{CF}$ increased from 1 to 2.4 as plant size index increased from 16 to $20 \mathrm{~cm}$ to 40 to $50 \mathrm{~cm}$.

The sprinkler irrigation system may also affect CF. Wobbler sprinkler heads resulted in better capture than impact sprinklers when close-spaced (51\% vs. $44 \%$ ) but not when separated (Beeson and Knox, 1991). Yeager and Beeson (1996) found that increasing the sprinkler nozzle height from $1.2 \mathrm{~m}$ to $3.6 \mathrm{~m}$ increased CF of trade \#3 Rhododendron spp. 'Formosa' from 1.6 to 1.9; nozzle placements greater than $3.6 \mathrm{~m}$ did not increase $\mathrm{CF}$.

The objectives of our experiments were to: 1) compare the irrigation capturing ability of some commonly grown ornamental plant species exhibiting a range of growth habits; 2 ) evaluate the effect that plant size, container diameter, and container spacing have on $\mathrm{CF}$; and 3) compare irrigation capture for wobbler vs. impact sprinklers.

\section{Materials and Methods}

Irrigation test site. A $6.1 \mathrm{~m} \times 6.1-\mathrm{m}$ irrigation area at the University of Florida, Gainesville, was used for CF experiments. Impact sprinkler heads (Maxijet 2045PJ-08 with No. 8 nozzles rated at $11.4 \mathrm{~L} \cdot \mathrm{min}^{-1}$; Rainbird Corp., Azusa, AZ) on 1.2-m tall risers fitted with $207-\mathrm{kPa}$ pressure regulators were situated at each of the four corners of the irrigation zone. Spray patterns were adjusted to achieve a Christiansen's Uniformity Coefficient (Burt et al., 1997) greater than $95 \%$ and a delivery rate of $1.4 \mathrm{~cm} \cdot \mathrm{h}^{-1}$. A $10 \mathrm{~m} \times 12-\mathrm{m}$ windbreak shelter composed of woven, polypropylene groundcloth attached to a metal frame structure around the perimeter of the irrigation zone provided wind protection during irrigation testing.

Expt. 1: Plant species comparison. Eleven ornamental plant species grown in $16-\mathrm{cm}$ diameter containers and 27-cm-diameter containers and representing various growth habits were surveyed for their capacity to capture 
sprinkler irrigation water: Agapanthus africanus (L.) Hoffsgg. (African Lily), Buxus microphylla var. japonica Siebold \& Zucc. (Japanese Boxwood), Ilex cornuta Lindl. \& Paxt. 'Burfordii Nana' (Burford Holly), Ilex vomitoria Aiton 'Nana' (Dwarf Yaupon), Jasminum multiflorum (Burm. f.) Andrews (Downy Jasmine), Juniperus chinensis L. 'Parsonii' (Parson's Juniper), Ligustrum japonicum Thunb. (Waxleaf Ligustrum), Podocarpus macrophyllus Thunb. (Podocarpus), Rhaphiolepis indica (L.) Lindl. ex Ker Gawl. (Indian Hawthorn), Rhododendron spp. L. 'Red Ruffles' (Red Ruffles Azalea), and Viburnum odoratissimum Ker Gawl. (Sweet Viburnum). The growth habits of the 11 species given in Table 1 are based on classification by the FDACS (2005). Ten marketable- or near marketable-sized plants of each plant species and container size were obtained from several commercial nurseries in Florida. Container manufacturers varied from species to species and in a few instances within the same species and container size group and so are not given here. Because the top area of the container was the only critical container attri- bute for this study, the average diameter of each container (two perpendicular measurements) was used in CF calculations to account for any differences in container diameter. We measured the height and width of each test plant. Plant height was the distance from the substrate surface to the top of the canopy. Plant width was the average of two perpendicular measurements of the plant canopy, one being the widest. Plant size index was calculated as the average of plant height and plant width.

Irrigation capture measurements entailed placing each container in a similar-sized pail to collect any leachate during testing. Aluminum foil was used to form a barrier between the container and drainage collection pail to prevent irrigation water from directly entering the drainage collection pail. For each plant species and container size, 10 preweighed container-pail assemblies were placed on $61-\mathrm{cm}$ centers in an equidistant, offset pattern. Containers were irrigated for $30 \mathrm{~min}$ applying $0.7 \mathrm{~cm}$ of water. After irrigation, each container-pail assembly was weighed and the difference in weight before and after irrigation was used to calculate $V_{p}$ based on the specific gravity of water $\left(1 \mathrm{~g} \cdot \mathrm{cm}^{-3}\right)$. The irrigation capture test was conducted three times for each plant species-container size resulting in a total of 30 measurements per plant species and container size.

The amount of water captured without a plant, $V_{o}$, was determined by placing empty pails in the same spacing pattern as plant irrigation capture tests and collecting irrigation water during three 30-min irrigation runs. The following equation was used to calculate $V_{o}$ :

$$
\begin{aligned}
V_{o}= & \frac{\text { container top area }(\mathrm{cm})}{\text { irrig. collection pail top area }(\mathrm{cm})} \\
& \times \text { irrigation volume }\left(\mathrm{cm}^{3}\right)
\end{aligned}
$$

Measured values for $V_{o}$ and $V_{p}$ were used to calculate $\mathrm{CF}$ according to Eq. [1].

The experiment was analyzed as a randomized complete block design with 10 blocks (locations in test area), 11 plant species, and three replications (irrigation events) using the PROC GLM procedure of the Statistical Analysis System (SAS ${ }^{\circledR}$ Institute, Cary, NC). We used Tukey's honest significant difference

\begin{tabular}{|c|c|c|c|c|c|c|c|}
\hline \multirow[b]{2}{*}{ Species } & \multirow[b]{2}{*}{ Growth habit ${ }^{\mathrm{y}}$} & \multicolumn{3}{|c|}{ 16-cm container } & \multicolumn{3}{|c|}{ 27-cm container } \\
\hline & & Plant ht $(\mathrm{cm})$ & Plant width $(\mathrm{cm})$ & $\mathrm{CF}$ & Plant ht $(\mathrm{cm})$ & Plant width $(\mathrm{cm})$ & $\mathrm{CF}$ \\
\hline Agapanthus africanus & $\mathrm{GC}$ & 18 & 32 & 1.17 & 37 & 59 & 1.57 \\
\hline Buxus microphylla var. japonica & US & 26 & 25 & 1.65 & 50 & 43 & 2.34 \\
\hline Ilex cornuta 'Burfordii Nana' & US & 31 & 34 & 1.66 & 47 & 53 & 1.79 \\
\hline Ilex vomitoria 'Nana' & SBS & 24 & 34 & 1.82 & 32 & 62 & 2.87 \\
\hline Jasminum multiflorum & SV & 32 & 47 & 1.54 & 61 & 59 & 2.27 \\
\hline Juniperus chinensis 'Parsonii' & BS & 29 & 48 & 1.98 & 27 & 72 & 2.39 \\
\hline Ligustrum japonicum & US & 44 & 46 & 3.09 & 75 & 73 & 4.12 \\
\hline Podocarpus macrophyllus & US & 63 & 45 & 3.16 & 95 & 60 & 4.08 \\
\hline Rhaphiolepis indica & $\mathrm{S}$ & 26 & 38 & 2.53 & 35 & 73 & 3.88 \\
\hline Rhododendron spp. 'Red Ruffle' & GL & 24 & 30 & 1.51 & 35 & 46 & 1.77 \\
\hline Viburnum odoratissimum & US & 32 & 42 & 2.25 & 65 & 73 & 4.20 \\
\hline $\mathrm{HSD}_{0.05}$ & & 6 & 5 & 0.24 & 5 & 5 & 0.30 \\
\hline
\end{tabular}

Table 1. Influence of plant species on the capture of sprinkler irrigation water at wide spacing arrangement (Expt. 1). ${ }^{\mathrm{z}}$

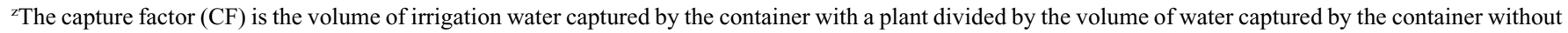
a plant. Separate analysis of variance tests were conducted for $16-\mathrm{cm}$ - and 27 -cm-diameter containers.

${ }^{\mathrm{y}} \mathrm{GC}=$ groundcover; US = upright spreading; $\mathrm{SBS}=$ semibroad spreading; $\mathrm{SV}=$ spreading vine; $\mathrm{BS}=$ broad spreading; $\mathrm{S}=$ spreading; GL = globose $($ Florida Department of Agriculture and Consumer Services, 2005).

$\mathrm{HSD}=$ honest significant difference.

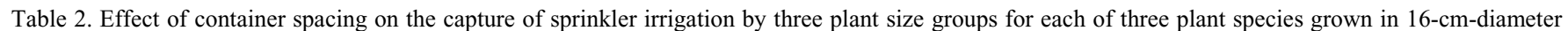

\begin{tabular}{|c|c|c|c|c|c|c|c|c|c|c|}
\hline \multirow[b]{3}{*}{ Plant size group } & \multirow[b]{3}{*}{ Plant ht $(\mathrm{cm})$} & \multirow[b]{3}{*}{ Plant width $(\mathrm{cm})$} & \multicolumn{7}{|c|}{$\mathrm{CF}$} & \multirow[b]{3}{*}{$\mathrm{HSD}_{0.0}$} \\
\hline & & & \multicolumn{7}{|c|}{ Equidistant spacing $(\mathrm{cm} \text { between containers })^{\mathrm{y}}$} & \\
\hline & & & 0 & $3.8^{x}$ & 5.1 & 7.6 & 10.2 & 15.2 & 22.9 & \\
\hline \multicolumn{11}{|c|}{ Juniperus chinensis 'Parsonii' } \\
\hline Small & 20 & 25 & 1.09 & 1.15 & 1.14 & - & 1.10 & - & - & 0.06 \\
\hline Medium & 25 & 36 & - & 1.43 & 1.68 & - & 1.88 & 1.96 & - & 0.08 \\
\hline Large & 28 & 43 & - & - & 1.98 & - & 2.41 & 2.72 & 2.79 & 0.18 \\
\hline \multicolumn{11}{|c|}{ Rhaphiolepis indica } \\
\hline Small & 18 & 25 & 1.23 & 1.41 & - & 1.37 & - & 1.32 & - & 0.11 \\
\hline Medium & 20 & 30 & - & 1.57 & - & 1.81 & - & 1.85 & 1.80 & 0.14 \\
\hline Large & 25 & 38 & - & 1.62 & - & 1.84 & - & 2.46 & 2.41 & 0.18 \\
\hline \multicolumn{11}{|c|}{ Ligustrum japonicum } \\
\hline Small & 30 & 30 & 1.30 & 1.60 & - & 1.87 & - & 2.04 & - & 0.15 \\
\hline Medium & 36 & 38 & - & 1.85 & - & 2.24 & - & 2.60 & 2.62 & 0.19 \\
\hline Large & 46 & 51 & - & 1.84 & - & 2.06 & - & 2.88 & 3.34 & 0.21 \\
\hline
\end{tabular}
containers (Expt. 2). ${ }^{\mathrm{z}}$

${ }^{z}$ The capture factor (CF) is the relative amount of water captured by a container with a plant versus the amount that would be captured without a plant. An analysis of variance was conducted for each of three size groups per plant species $(n=21)$. Tukey's honest significant difference $\left(\mathrm{HSD}_{0.05}\right) \mathrm{values}$ are for comparing $\mathrm{CF}$ means within the same row.

${ }^{y}$ Area ratio (total area/container top area) $=1.1,1.7,1.9,2.4,3.0,4.2$, and 6.5 for the 0-, 3.8-, 5.1-, 7.6-, 10.2-, 15.2-, and 22.9-cm spacings, respectively. x2.5 for Juniper. 
option for separating $\mathrm{CF}$ means at the 5\% confidence level.

Expt. 2: Plant size and container spacing. To evaluate the effect of plant size and container spacing on $\mathrm{CF}$, we selected three plant species from Expt. 1 that exhibited different growth habits and water-capturing abilities: Juniperus chinensis 'Parsonii', Rhapheolepis indica, and Ligustrum japonicum. Three general plant size groups (small, medium, large) of each of the three plant species and two container sizes $(16 \mathrm{~cm}$ and $27 \mathrm{~cm}$ diameter) were obtained from a commercial nursery. Depending on the plant species, plant size, and container size, $\mathrm{CF}$ was measured at four container spacings ranging from canopies close together $(0 \mathrm{~cm})$ to canopies far apart $(22.9 \mathrm{~cm})$ (Table 2$)$. CF was measured using the same methods described in Expt. 1 except that only seven test plants were used. Plant height and width were determined for each test plant. Twelve border plants were placed around the seven test plants in the same spacing arrangement as the test plants to maintain the same canopy interaction effects for all test plants (Fig. 1). The effect of spacing was evaluated with analysis of variance (ANOVA) conducted

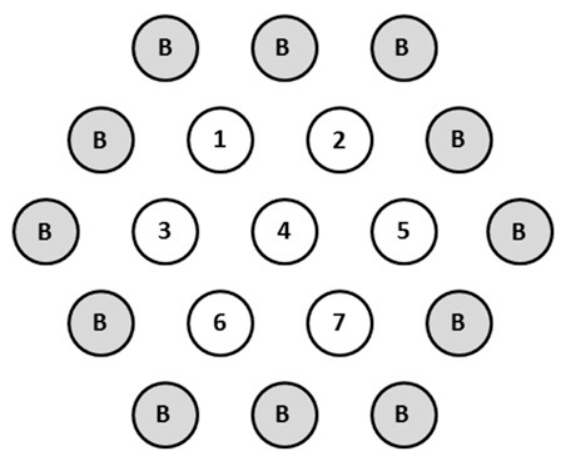

Fig. 1. Arrangement of test plants used to measure the effect of plant size, container size, and container spacing on the capture of sprinkler irrigation (Expt. 2). Seven test plants were surrounded by 12 border (B) plants. separately for each species, container size, and plant size group. For each plant species and container size, linear regression was used to relate plant height, plant width, and plant size index to CF measured at the widest spacing.

Expt. 3: Sprinkler head type-wobbler versus impact. Wobbler sprinklers were compared with impact sprinklers for their effect on irrigation water capture using L. japonicum in 16-cm- and 27-cm-diameter containers. The impact sprinklers used were the same as those used in Expts. 1 and 2. Wobbler sprinklers (\#8 Mini Wobbler; Senninger Irrigation Inc., Clermont, FL) were installed on the same risers as the impact sprinklers used in Expts. 1 and 2, but the 207-kPa pressure regulators were replaced with 139-kPa pressure regulators per the manufacturer's recommendation. Irrigation uniformity and application rate were measured for both sprinkler types by collecting irrigation water in $2016-\mathrm{cm}$ diameter pails placed in a $4.6 \mathrm{~m} \times 4.6-\mathrm{m}$ area within

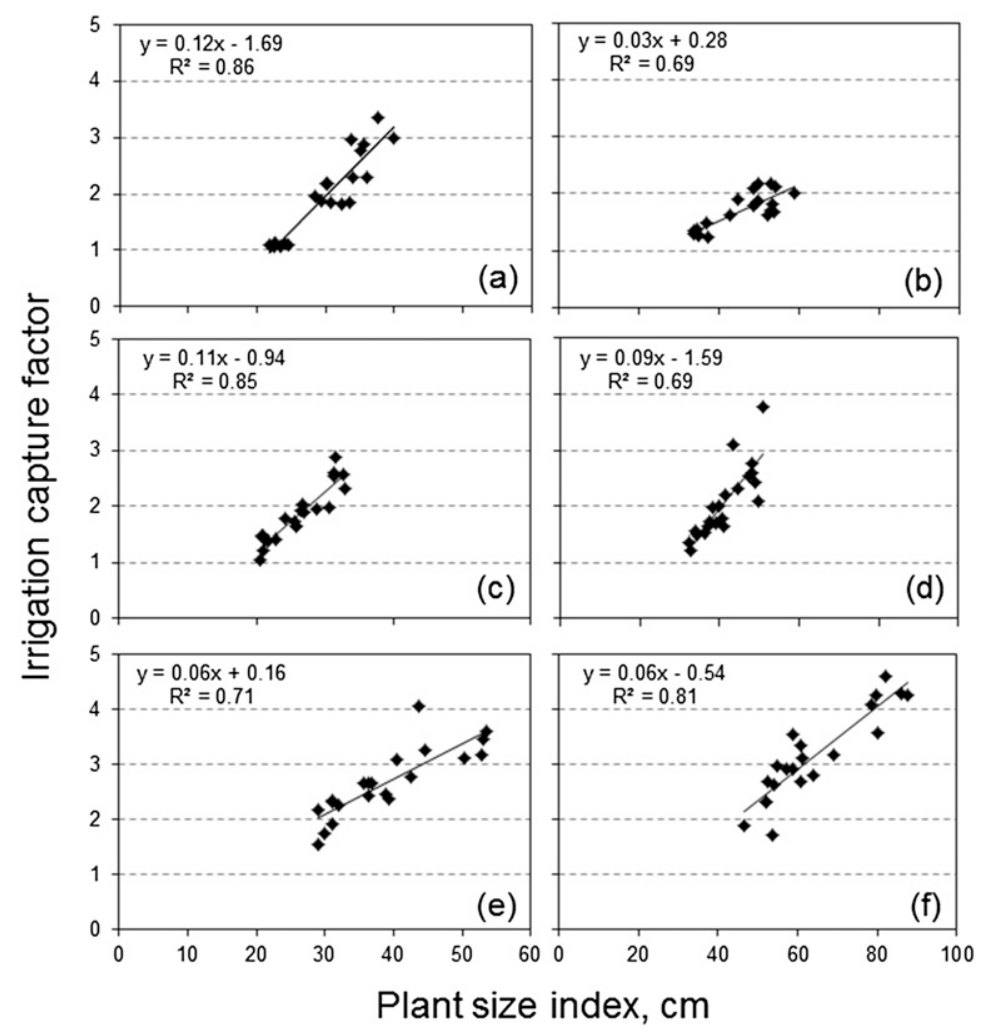

Fig. 2. Effect of plants size index on the irrigation capture factor (CF) of Juniperus chinensis 'Parsonii' (A-B), Rhaphiolepis indica $(\mathbf{C}-\mathbf{D})$, and Ligustrum japonicum $(\mathbf{E}-\mathbf{F})$ grown in 16-cm diameter $(\mathbf{A}, \mathbf{C}$, E) and 27-cm (B, D, F) diameter containers (Expt. 2). Symbols represent the mean of 21 measurements made at the widest spacing tested for each species and plant size group (Table 2). CF = volume of sprinkler irrigation water captured by the container divided by the volume that would be captured by the container without a plant.

Table 3. Effect of container spacing on the capture of sprinkler irrigation by three plant size groups for each of three plant species grown in 27-cm-diameter containers (Expt. 2). ${ }^{z}$

\begin{tabular}{|c|c|c|c|c|c|c|c|c|}
\hline \multirow[b]{3}{*}{ Plant size group } & \multirow[b]{3}{*}{ Plant ht $(\mathrm{cm})$} & \multirow{3}{*}{$\begin{array}{c}\text { Plant } \\
\text { width }(\mathrm{cm})\end{array}$} & \multicolumn{5}{|c|}{$\mathrm{CF}$} & \multirow[b]{3}{*}{$\mathrm{HSD}_{0.05}$} \\
\hline & & & \multicolumn{5}{|c|}{ Equidistant spacing $\left(\mathrm{cm}\right.$ between containers) ${ }^{y}$} & \\
\hline & & & 7.6 & 15.2 & 22.9 & 30.5 & 38.1 & \\
\hline \multicolumn{9}{|c|}{ Juniperus chinensis 'Parsonii' } \\
\hline Medium & 38 & 58 & - & 1.72 & 1.74 & 1.9 & - & 0.09 \\
\hline Large & 41 & 69 & - & 1.77 & 1.88 & 1.89 & - & 0.12 \\
\hline \multicolumn{9}{|c|}{ Rhaphiolepis indica } \\
\hline Small & 28 & 41 & 1.46 & 1.56 & 1.50 & - & - & 0.07 \\
\hline \multicolumn{9}{|c|}{ Ligustrum japonicum } \\
\hline Small & 51 & 53 & 1.82 & 1.99 & 2.17 & 2.35 & & 0.12 \\
\hline Medium & 58 & 64 & - & 2.53 & 2.94 & 2.98 & 3.04 & 0.12 \\
\hline Large & 81 & 81 & - & 2.91 & 3.47 & 3.86 & 4.02 & 0.20 \\
\hline
\end{tabular}

${ }^{z}$ The capture factor $(\mathrm{CF})$ is the relative amount of water captured by a container with a plant versus the amount that would be captured without a plant. An analysis of variance was conducted for each of three size groups per plant species $(n=21)$. Tukey's honest significant difference $\left(\mathrm{HSD}_{0.05}\right) \mathrm{values}$ are for comparing $\mathrm{CF}$ means within the same row.

${ }^{\mathrm{y}}$ Area ratio (total area/container top area) $=1.8,2.7,3.8,5.0$, and 6.4 for the 7.6-, 15.2-, 22.9-, 30.5-, and 38.1-cm spacings, respectively. 
the irrigation wind shelter. Irrigation run time for irrigation uniformity tests was $45 \mathrm{~min}$ and tests were repeated four times for each sprinkler type. The irrigation application rate was $1.27 \mathrm{~cm} \cdot \mathrm{h}^{-1}$ for impact sprinklers and 1.55 $\mathrm{cm} \cdot \mathrm{h}^{-1}$ for wobbler sprinklers. Christiansen's Coefficients of Uniformity were greater than $96 \%$ for both sprinkler types.

For CF testing, seven marketable-sized plants in $16-\mathrm{cm}$ - or $27-\mathrm{cm}$-diameter containers were placed in an offset pattern with one container diameter spacing between rims of adjacent containers. Twelve border plants were placed around the seven test plants in the same spacing arrangement as the test plants. The irrigation run time for $\mathrm{CF}$ testing was $30 \mathrm{~min}$ for impact sprinklers and $35 \mathrm{~min}$ for wobblers. CF was measured for each of the seven test plants as described in Expt. 1 and there were three irrigation test applications for each sprinkler type and container size. Plant height and width for all test plants was measured as described in Expt. 1.

The experiment was analyzed as a randomized complete block design with two treatments (sprinkler type), seven blocks (plants), and three replications (irrigations). An ANOVA was carried out independently by Tukey's honest significant difference when treatment effects were significant at the $5 \%$ confidence level. for each container size. Mean separation was

\section{Results and Discussion}

Expt. 1: Plant species comparison. Plant species exhibited a wide range of water-capturing abilities (Table 1). CF values for marketable-sized plants ranged from 1.2 to 4.2 depending on container size and plant species. Lowest $\mathrm{CF}$ values were observed for the groundcover Agapanthus africanus, which exhibited a "weeping" canopy shape. The downward arcing of the leave blades outside the container perimeter likely resulted in the relatively low $\mathrm{CF}$ values compared with the other species tested. The globose-shaped azalea (Rhododendron spp. 'Red Ruffle') exhibited moderately low CFs (1.5 and 1.8 for $16-\mathrm{cm}$ and $27-\mathrm{cm}$ container, respectively). Three small-leaved species, Buxus microphylla var. japonica, Ilex cornuta, and Ilex vomitoria, exhibited moderate $\mathrm{CF}$ values ranging from 1.7 to 2.9. The spreading vine Jasmine multiflorum and the broad-spreading Juniperus chinensis 'Parsonii' also exhibited moderate CF values. For J. multiflorum, branches tended to droop outside the container perimeter so that although plants were tall and wide, channeling of water into the container was moderate. For $J$. chinensis, low plant height from its broad-spreading habit appeared to limit the ability of the canopy to channel water into containers.

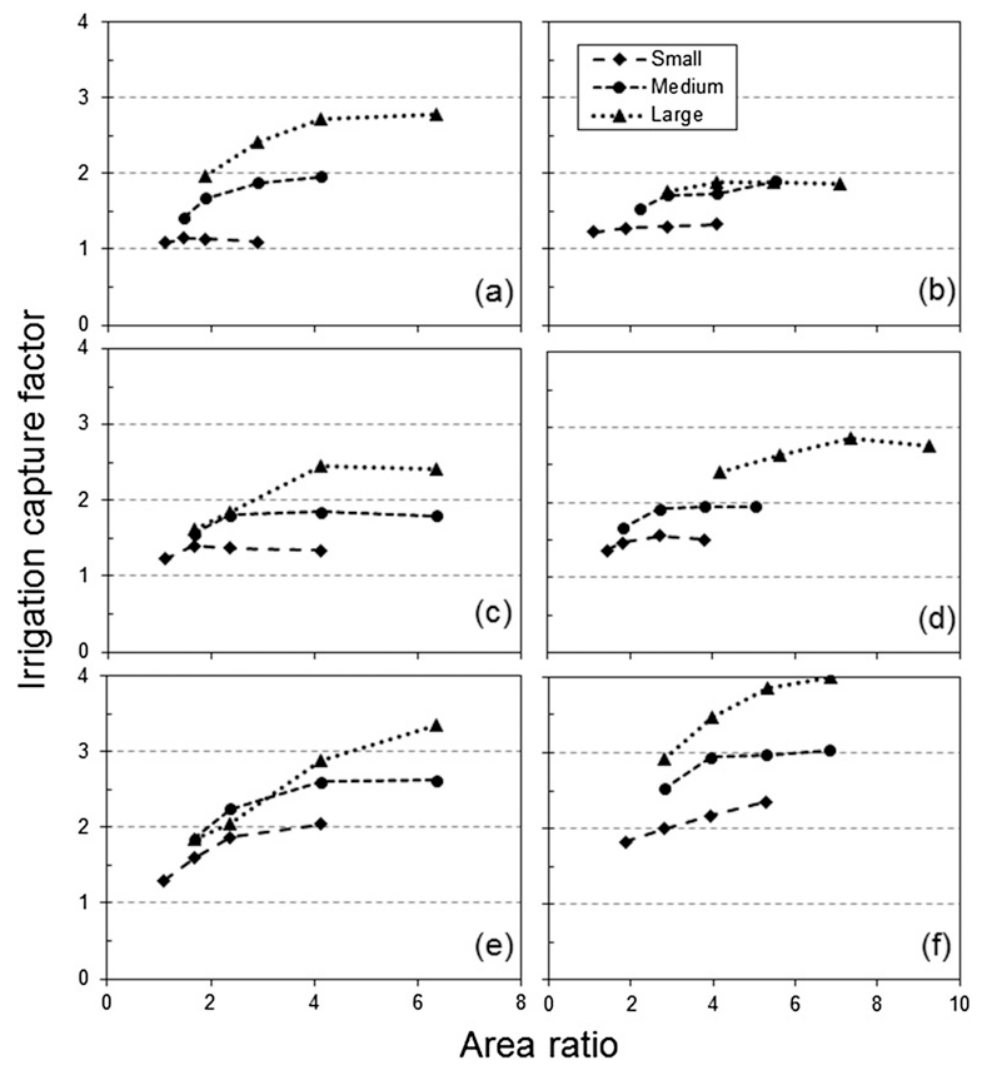

Fig. 3. Effect of area ratio ( $\mathrm{AR}=$ area allotted container/top area of container $)$ on the irrigation capture factor (CF) of Juniperus chinensis 'Parsonii' (A-B), Rhaphiolepis indica (C-D), and Ligustrum japonicum $(\mathbf{E}-\mathbf{F})$ grown in $16-\mathrm{cm}$ diameter $(\mathbf{A}, \mathbf{C}, \mathbf{E})$ and $27-\mathrm{cm}(\mathbf{B}, \mathbf{D}, \mathbf{F})$ diameter containers (Expt 2). Symbols represent the mean of 21 measurements made for three plant size groups tested at four spacings per species and container size. $\mathrm{CF}=$ volume of sprinkler irrigation water captured by the container divided by the volume that would be captured by the container without a plant.
Highest CF values (2.3 to 4.2) were observed for several woody shrubs with an upright-spreading growth habit: Ligustrum japonicum, Podocarpus macrophyllus, and Viburnum odoratissimum. A fourth species, Rhaphiolepis indica, also exhibited high CF (2.5 and 3.9). Although $R$. indica's habit is spreading, branches within the canopy were upright resulting in high $\mathrm{CF}$ despite relatively low height-to-width ratio.

Beeson and Yeager (2003) observed much lower CF values than observed in our study. Average $C F$ values measured at wide spacings did not exceed 1 for either L. japonicum or $V$. odoratissimum. The diaper they placed on the substrate surface to collect captured water may not have effectively captured water channeling down the stem. We noticed that these two high water-capturing species channel water down the main stem in a relatively heavy flow. Perhaps the stem flow bypassed the diaper causing the ineffective capture. Evidence for this is the low CF values (?0.5) observed at the 0 spacing where containers in a square arrangement occupied $79 \%$ of the production area leaving relatively little area outside the container to receive unintercepted irrigation water.

Based on results, we found plants classified as groundcover or globose to exhibit the lowest CF values, semibroad spreading, broad spreading, and spreading vine habits to exhibit moderate $\mathrm{CF}$ values, and upright spreading habits to have moderate to high CFs. In general, large-leafed species and species with greater height-to-width ratios tended to have higher CFs than plant species with smaller leaves and more spreading growth.

Expt. 2: Plant size and container spacing. $\mathrm{CF}$ increased as plant size of each plant species increased (Tables 2 and 3 ). We found that plant size index was more highly correlated with $\mathrm{CF}$ than height and width alone. A linear relationship between plant size index and CF measured at the widest spacing (typically the highest measured CF) was significant for each of the three species and for each of the two container sizes (Fig. 2). Although the linear equations can be used to

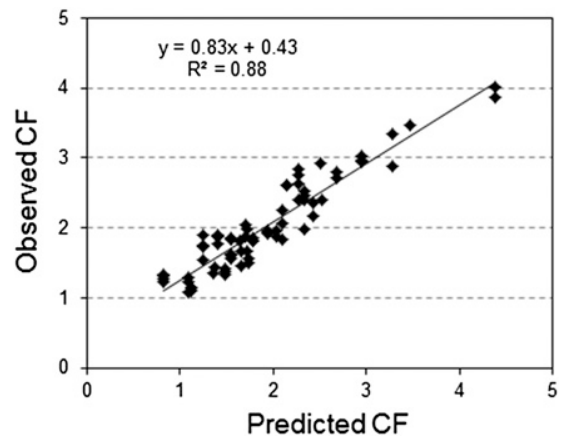

Fig. 4. Relationship between predicted and observed irrigation capture factor (CF) using a model based on plant size, container size, container spacing, and maximum irrigation capture. Symbols represent the mean of 21 observations for each of 72 treatments (three species $\times$ two container sizes $\times$ three plant size groups $\times$ four spacings). 
Table 4. Effect of sprinkler type on irrigation capture by Ligustrum japonicum in 16-cm- and 27-cmdiameter containers (Expt. 3). ${ }^{\mathrm{z}}$

\begin{tabular}{cccccc}
\hline & & \multicolumn{3}{c}{ CF } \\
\cline { 3 - 5 } Container diam $(\mathrm{cm})$ & Plant ht $(\mathrm{cm})$ & Plant width $(\mathrm{cm})$ & Impact & Wobbler & HSD $_{0.05}{ }^{\mathrm{y}}$ \\
\hline 16 & 35 & 41 & 2.89 & 2.95 & $\mathrm{NS}$ \\
27 & 59 & 62 & 3.39 & 3.63 & 0.12 \\
\hline
\end{tabular}

${ }^{\mathrm{z}}$ Capture factor $(\mathrm{CF})$ is the amount of water captured by a container with a plant relative to the amoun captured without a plant.

${ }^{y}$ Analysis of variance conducted separately for each container diameter. Tukey's honest significant difference (HSD) $(\mathrm{n}=21)$ is for comparing sprinkler type means within the row (container diameter). NS $=$ nonsignificant at $5 \%$ confidence level.

estimate CF based on plant size index, they can also be used to estimate the minimal plant size index where irrigation capture is enhanced (i.e., $\mathrm{CF}$ greater than 1.0). This minimal plant size index was 22,18 , and 14 cm for J. chinensis, R. indica, and L. japonicum, respectively, in $16-\mathrm{cm}$ containers and 24,29 , and $26 \mathrm{~cm}$, respectively, in $27-\mathrm{cm}$ containers. These results indicate that the three species exhibited enhanced irrigation water capture when plant size was approximately equal to the container diameter.

Container spacing is another factor that affected CF (Tables 2 and 3). Container spacing imposes a physical limitation on potential water capture because each plant, on average, can only capture water within the area allotted the container. If we define the area ratio (AR) as the area allotted each container divided by the top area of the container, then the theoretical maximum $\mathrm{CF}$ $(C F \max )$ is limited to AR. Area ratios for the container spacings tested are given as footnotes to Tables 2 and 3 .

For a given plant size group, measured $\mathrm{CF}$ was limited beyond that indicated by AR alone (Fig. 3). For example, the medium-sized group of L. japonicum in 16-cm containers had a CF = 2.2 at $\mathrm{AR}=2.4$ and 2.6 at $\mathrm{AR}=4.2$ (Fig. 3E). The medium-sized group in $27-\mathrm{cm}$ containers had a $\mathrm{CF}=2.5$ at $\mathrm{AR}=2.7$ and $\mathrm{CF}=2.9$ at $\mathrm{AR}=3.8$ (Fig. 3F). To quantify this reduction in $\mathrm{CF}$ beyond that indicated by AR alone, we found that limiting the capture of water to $80 \%$ of the water that would fall between containers if no plant was there gave reasonable results for the range of plant sizes evaluated in this experiment. An equation for CFmax based on this premise can be simplified to:

$$
C F \max =0.8 \mathrm{AR}+0.2
$$

CFmax can be used in predictive models to establish a maximum value that is slightly smaller than the theoretical maximum indicated by AR alone. A model using plant size index to estimate $\mathrm{CF}$ (Fig. 2) and limiting $\mathrm{CF}$ to $C F \max$ [Eq. (3)] gave estimated $\mathrm{CF}$ values that agreed well with measured $C F$ values for both container sizes and the three plant size groups tested for each of the three species (Fig. 4). In lieu of directly monitoring $\mathrm{CF}$, similar plant size index functions developed for plant species being grown could be used to estimate $\mathrm{CF}$ during production and thus irrigation rates could be adjusted accordingly.

Expt. 3: Sprinkler type-wobbler versus impact. Wobbler sprinklers resulted in greater irrigation water capture by L. japonicum in $27-\mathrm{cm}$ containers but not $16-\mathrm{cm}$ containers (Table 4). For 27-cm containers, wobbler sprinklers increased CF 7\% compared with impact sprinklers. The ability of wobbler sprinklers to deliver water uniformly at a lower pressure than impact sprinklers may have reduced the force of impact of water on the plant canopy. Reduced force of impact as such may have increased retention of the water and enhanced subsequent channeling down leaves and stems to the container substrate. Based on mixed results from this study and from Beeson and Knox (1991), wobbler sprinklers improved irrigation capture in certain instances but the effect was not found to be great (less than $10 \%$ increase) or consistent.

\section{Conclusions}

Results of the experiments indicate that the $\mathrm{CF}$ is a dynamic value that depends on plant species, plant size, container size, container spacing, and nozzle type. Growth habit and canopy characteristics determine to what extent a plant species can affect the capture of sprinkler irrigation water. In general, plant species with upright, spreading canopies (e.g., L. japonicum) exhibited the highest water-capturing abilities. Plant size index was found to be a good indicator for estimating the increase in CF that occurs as plants grow in size during the season. Container size and spacing were shown to affect CF by imposing a physical limitation to the amount of water available for capture. In general, CF was not limited if the spacing between containers was at least one container diameter apart.

CF can play a critical role in adjusting irrigation run times to apply a required amount of water to containers. Grouping plants with similar irrigation requirements within container nurseries is a best management practice (FDACS, 2014). It follows that the plant's irrigation-capturing ability as indicated by $\mathrm{CF}$ should be included in plant grouping considerations.

\section{Literature Cited}

Beeson, R.C. 2010. Modeling actual evapotranspiration of Viburnum odoratissimum during production from rooted cuttings to market size plants in 11.4-L containers. HortScience 45:1260-1264.

Beeson, R.C. 2011. Weighing lysimeters for quantifying water use and studies of controlled water stress for crops grown in low bulk density substrates. Agr. Water Mgt. 98:967-976.

Beeson, R.C., M.A. Arnold, T.E. Bilderback, B. Bolusky, S. Chandlef, H.M. Gramling, J.D. Lea-Cox, J.R. Harris, P.J. Klinger, H.M. Mathers, J.M. Ruter, and T.H. Yeager. 2004. Strategic vision of container nursery irrigation in the next ten years. J. Environ. Hort. 22:113-115.

Beeson, R.C. and G.W. Knox. 1991. Analysis of efficiency of overhead irrigation in container production. HortScience 26:848-850.

Beeson, R.C. and T.H. Yeager. 2003. Plant canopy affects sprinkler irrigation application efficiency of container-grown ornamentals. HortScience 38:1373-1377.

Bergeron, O., M.S. Lamhamedi, H.A. Margolis, and P.Y. Bernier. 2004. Irrigation control and physiological responses of nursery-grown black spruce seedling $(1+0)$ cultivated in airlit containers. HortScience 39:599-605.

Bilderback, T.E., J.M. Dole, and R.E. Sneed. 2011. Greenhouse and nursery irrigation practices, p. 808-852. In: Stetson, L.E. and B.Q. Mecham (eds.). Irrigation. 6th Ed. Irrigation Assoc., Falls Church, VA.

Burt, C.M., A.J. Clemmens, and K.H. Strelkoff. 1997. Irrigation performance measures: Efficiency and uniformity. J. Irrig. Drain. Eng. 123:423-442.

Florida Department of Agriculture and Consumer Services. 2005. Grades and standards for nursery plants. Division of Plant Industry. p. 94-100. FDACS, Tallahassee, FL.

Florida Department of Agriculture and Consumer Services. 2014. Water quality/quantity best management practices for Florida nurseries. DACS P-01267. p. 16.

Million, J., T. Yeager, and J. Albano. 2010. Evapotranspiration-based irrigation scheduling for reducing runoff during production of $\mathrm{Vi}$ burnum odoratissimum (L.) Ker Gawl. HortScience 45:1741-1746.

Million, J.B., J.T. Ritchie, T.H. Yeager, C.A. Larsen, C.D. Warner, and J.P. Albano. 2011. CCROP-Simulation model for containergrown nursery plant production. Sci. Hort. 130:874-886.

Murray, J.D., J.D. Lea-Cox, and D.S. Ross. 2004 Time domain reflectometery accurately monitors and controls irrigation water applications. Acta Hort. 633:75-82.

Owen, J.S., S.L. Warren, and T.E. Bilderback. 2007. A gravimetric approach to real-time monitoring of substrate wetness in containergrown nursery crops. Acta Hort. 819:317-324.

Schuch, U.K. and D.W. Burger. 1997. Water use and crop coefficients of woody ornamentals in containers. J. Amer. Soc. Hort. Sci. 122:727734.

Yeager, T.H. and R.C. Beeson. 1996. Irrigation nozzle height influences water captured by containers. Proc. South. Nursery Assn. Res. Conf. 41:363-365. 